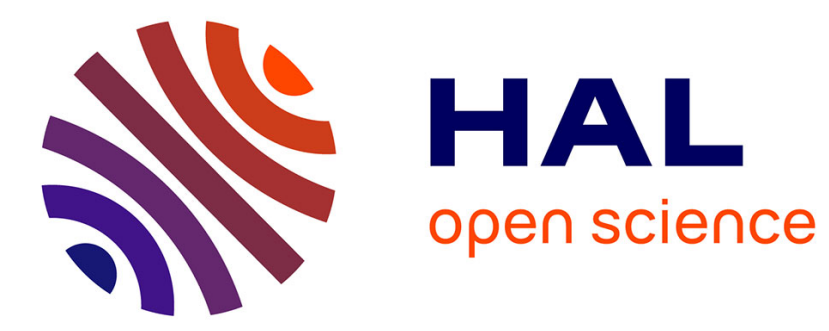

\title{
Two laboratory methods of assessing annoyance due to railway noise and vibration
}

Philéas Maigrot, Catherine Marquis-Favre, Etienne Parizet

\section{To cite this version:}

Philéas Maigrot, Catherine Marquis-Favre, Etienne Parizet. Two laboratory methods of assessing annoyance due to railway noise and vibration. Journal of the Acoustical Society of America, 2017, 142 (5), pp.3284. 10.1121/1.5012739 . hal-01711226

\section{HAL Id: hal-01711226 \\ https://hal.science/hal-01711226}

Submitted on 16 Feb 2018

HAL is a multi-disciplinary open access archive for the deposit and dissemination of scientific research documents, whether they are published or not. The documents may come from teaching and research institutions in France or abroad, or from public or private research centers.
L'archive ouverte pluridisciplinaire HAL, est destinée au dépôt et à la diffusion de documents scientifiques de niveau recherche, publiés ou non, émanant des établissements d'enseignement et de recherche français ou étrangers, des laboratoires publics ou privés. 


\title{
Two laboratory methods of assessing annoyance due to railway noise and vibration \\ Running title: Combined noise and vibration: methodological issues
}

\author{
Philéas Maigrot and Catherine Marquis-Favre* \\ Univ Lyon, École Nationale des Travaux Publics de l'Etat, \\ Laboratoire Génie Civil et Bâtiment (LGCB), \\ 3 rue Maurice Audin, F-69518 Vaulx-en-Velin, France \\ Étienne Parizet \\ Univ Lyon, Institut National des Sciences Appliquée de Lyon, \\ Laboratoire Vibrations et Acoustique (LVA), \\ 25 bis avenue Jean Capelle F-69621 Villeurbanne, France
}

(Dated: February 16, 2018)

\begin{abstract}
In laboratory experiments, total annoyance due to combined noise and vibration, and partial annoyances due to each source in the presence of the other, can be assessed in two ways: during separate sessions dedicated to the evaluation of each kind of annoyance, and during the same session. This paper examines the difference between annoyance responses provided by the two methods. No differences were found between partial (respectively total) annoyance responses measured during separate sessions and those measured during the same session. The latter procedure allows reducing the number of stimuli to which the participants are subjected.
\end{abstract}

PACS numbers: 43.50.Qp, 43.50.Sr, 43.40.Ng

\footnotetext{
* catherine.marquisfavre@entpe.fr
} 


\section{INTRODUCTION}

Railway traffic has been increasing in Europe over the last few decades, especially in large urban areas. Annoyance due to railway noise has been widely studied, as has annoyance due to combined noise sources, i.e. when railway noise is heard in the presence of other noise sources (e.g. road traffic, cf. [1] for a review on the topic of combined noises). Railway noise is often linked to building vibration caused by passing trains. This vibration propagates through the ground, from the tracks to inside adjacent houses. It may be perceptible and cause annoyance ([2]). Until now, only a small number of studies have been conducted to investigate annoyance due to combined noise and vibration (cf. [3] for a review). More laboratory and in situ studies are needed to further understand perceptual mechanisms when both types of exposure are involved.

Studies dealing with annoyance due to combined sources distinguish specific annoyance, partial annoyance and total annoyance. Specific annoyance refers to the annoyance due to one source in isolation. Partial annoyance (primarily defined by [4]) refers to annoyance due to one source (e.g. noise) in the presence of another one (e.g. vibration). Annoyance due to all sources combined is referred to as total (or overall) annoyance. Annoyance responses can be collected during in situ and laboratory studies, making it possible to understand the phenomena involved and to propose annoyance models.

During in situ studies ([5]), partial and total annoyance responses are commonly assessed within the same questionnaire. In the literature, one question asked is whether the order of the questions on annoyance affects annoyance responses ([6]). In studies conducted in the laboratory on combined noise sources, participants are asked during the same session to rate partial and total annoyance after each stimulus has been presented (e.g. [7]). In this case, it is interesting to know whether participants compromise between the different annoyance responses. For combined noise and vibration exposures, partial annoyances and total annoyance are commonly assessed during separate sessions. To our knowledge, no studies have been conducted to determine a potential difference between partial and total annoyance responses collected during the same session and during separate sessions. The goal of this study was to measure the influence of two laboratory methods used to assess partial and total annoyances due to railway noise and vibration on the participants' answers. The initial hypothesis was that both methods would lead to similar results. The stimuli 
were a set of 16 combinations of railway noise and vibration recorded in a dwelling close to a railway track. Partial and total annoyance responses were collected during separate sessions dedicated to evaluating each kind of annoyance after which they were assessed during the same session.

\section{METHOD}

\section{A. Participants}

Thirty-two adults $(20$ males, 12 females; mean age $=33.2$ years, standard deviation $=$ 9.7 years) took part in this experiment. An audiogram was measured before the experiment to ensure that they had normal hearing abilities. They were naive concerning the goal of the study and could ask any question about the experiment if it was not related to the objective of the study. Participants' written consent was obtained in accordance with the Helsinki declaration.

\section{B. Stimuli}

The noise and vibration stimuli were recorded simultaneously inside a house during a train passage. The noise was recorded using a stereophonic system, along with an omnidirectional microphone to calibrate recordings, as in previous studies ([8]). Vibration was recorded using an accelerometer Piezotronics 393B12 (PCB Piezotronics, Depew, NY, www.pcb.com) operating in the frequency range of interest (i.e. between 1 and $80 \mathrm{~Hz}$ for whole-body vibration). The railway track was approximately 10 meters from the building facade. Recordings took place in the center of a bedroom where the inhabitant reported the strongest vibration, in conformity with ISO 2631-2 ([9]). The position of the microphones was approximately 1.5 meters above the ground.

The duration of the extracted pass-by was 13.5 seconds. The spectrum of the extracted acoustic signal was broad band and the frequency range varied between $40 \mathrm{~Hz}$ and $20 \mathrm{kHz}$ while the dominant frequency of the vibration signal was $55 \mathrm{~Hz}$. Based on these acoustic and vibration signals, noise stimuli and vibration stimuli were presented at 4 different levels. The equivalent sound levels, $L_{A_{e q}}$, of the 4 noise stimuli $N_{1}, N_{2}, N_{3}$ and $N_{4}$, were 44, 50, 56 and $62 d B(A)$, respectively. The lowest level of $44 d B(A)$ corresponded to the level of 
the recorded pass-by with no gain applied. The unweighted root-mean-square (r.m.s.) accelerations of the 4 vibration stimuli $V_{1}, V_{2}, V_{3}$ and $V_{4}$, averaged over the total duration of the pass-by, were $0.0299,0.0543,0.0714$ and $0.0943 \mathrm{~m}_{\mathrm{s}} \mathrm{s}^{-2}$, respectively. The lowest r.m.s. acceleration of $0.0299 \mathrm{~m} . \mathrm{s}^{-2}$ corresponded to the acceleration measured on site. These levels were chosen according to the literature $([10],[11])$. Therefore, there were 16 combinations $N_{i} V_{j}$ of noise and vibration $(i=1: 4, j=1: 4)$.

\section{Apparatus}

Vibration was generated in the vertical direction by an electrodynamic shaker LDS-V650 (B\&K, Nærum, Denmark, www.bksv.com). The participants sat on a rigid stool secured to a platform mounted on the shaker. A guardrail was placed around the platform as a safety precaution for the participants. They were told not to lean against it and to maintain their bodies in a vertical posture during the experiment. Noise was presented through two loudspeakers (Tapco S5) placed in front of each participant so that they formed an equilateral triangle with the participant's head. The experiment was performed in a semianechoic chamber with background noise below $30 d B(A)$. Lastly, a touch screen was placed in front of the participant to display instructions and annoyance scales.

\section{Procedure}

At the beginning of the experiment, the participants were trained so that they could familiarize themselves with the stimulus range and annoyance scale. A numerical continuous scale was used, ranging from 0 ("not at all") to 10 ("extremely"), adapted from the ICBEN recommendations ([12]). Four stimuli were presented during this training period: a "weak" combination of the lowest noise and vibration levels, a "strong" combination of the highest noise and vibration levels, a stimulus composed of noise alone and a stimulus composed of vibration alone. After this training period, the experiment consisted of four sessions: A, B, $\mathrm{C}$ and D. The participants engaged in each session in random order. During each of these sessions, they were exposed to the 16 combinations of noise and vibration, also in random order. The participants had to rate their annoyance after each stimulus:

- During session A, the participants had to evaluate partial annoyance due to the noise 
heard within each of the 16 combined stimuli $N_{i} V_{j}$. During this session, specific annoyance due to the 4 noise stimuli $N_{i}$ in isolation was also assessed (a total of 20 stimuli: $\left.16 N_{i} V_{j}+4 N_{i}\right)$.

- During session B, the participants had to evaluate partial annoyance due to the vibration felt within each of the 16 combined stimuli $N_{i} V_{j}$. During this session, specific annoyance due to the 4 vibration stimuli $V_{j}$ in isolation was also assessed (a total of 20 stimuli: $\left.16 N_{i} V_{j}+4 V_{j}\right)$.

- During session C, the participants had to evaluate total annoyance due to combined noise and vibration (16 stimuli $N_{i} V_{j}$ ).

- During session D, the participants were asked to evaluate partial annoyance due to noise, partial annoyance due to vibration and total annoyance due to combined noise and vibration (16 stimuli $N_{i} V_{j}$ ).

A stimulus could be played as many times as necessary before the annoyance response was given. This response could not be modified once the next stimulus had been played. At the end of each session, the participants were asked to rate the difficulty of the task on the same continuous numerical scale. The experiment lasted approximately 45 minutes.

\section{RESULTS}

The results were analyzed to evaluate potential differences between the annoyance measured using both procedures. Repeated-measures analyses of variance (RM-ANOVA) were carried out on the annoyance responses. All the post hoc analyses were carried out using Tukey's Honest Significant Difference (HSD) test. In order to focus on the comparison of both procedures, specific annoyance responses will not be considered in this paper. FIG. ?? indicates the mean noise annoyance responses $\left(A_{N}\right)$, mean vibration annoyance responses $\left(A_{V}\right)$ and total annoyance responses $\left(A_{T}\right)$, collected during sessions $\mathrm{A}$ and $\mathrm{D}$, during sessions $\mathrm{B}$ and $\mathrm{D}$ and during sessions $\mathrm{C}$ and $\mathrm{D}$, respectively. 
(a)

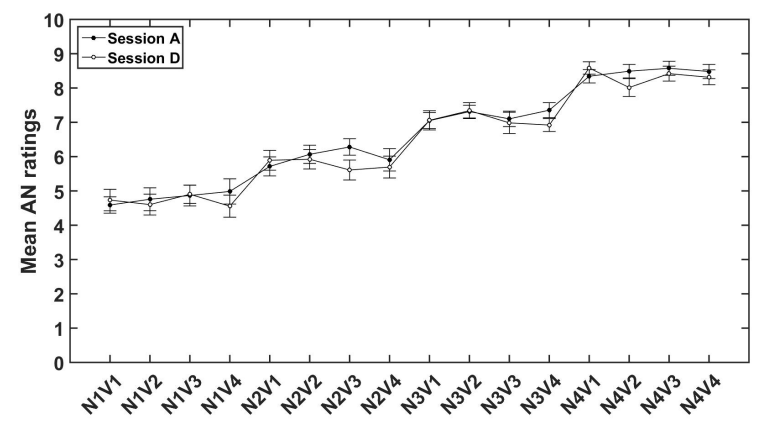

(b)

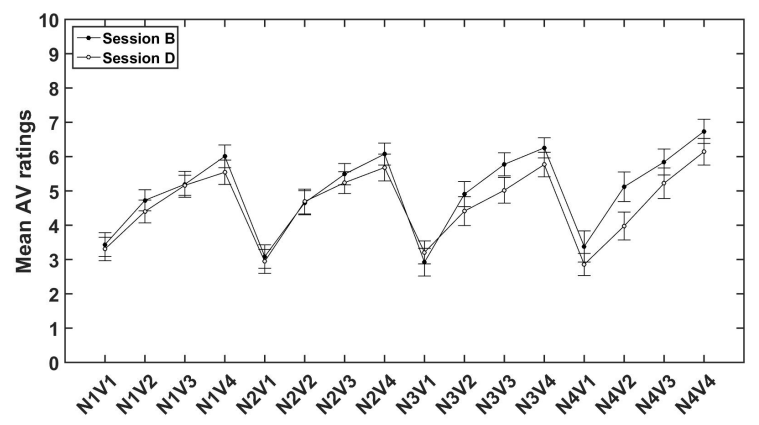

(c)

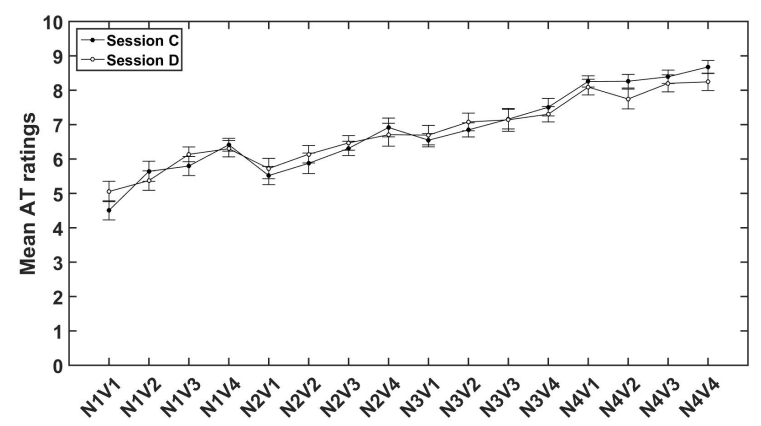

FIG. 1. Mean annoyance ratings and standard errors: (a) partial noise annoyance, (b) partial vibration annoyance and (c) total annoyance.

\section{A. Influence of the method on annoyance responses}

In order to study the influence of the method of collecting annoyance responses on the participants' answers, three one-factorial RM-ANOVAs were carried out, considering the factor SESSION. The results indicated that the effect of the session was not significant on $A_{N}$ responses $[F(1,31)=1.12, p>0.29], A_{V}$ responses $[F(1,31)=3.55, p>0.06]$ and $A_{T}$ responses $[F(1,31)=0.01, p>0.91]$.

\section{B. Influence of the method on task difficulty}

The difficulty ratings expressed at the end of each session were also analyzed using an onefactorial RM-ANOVA with the factor SESSION. The effect of the method on task difficulty was significant $[F(3,93)=5.7364, p<0.01]$. The proportion of variance $\eta^{2}$ explained by the factor SESSION was $2.4 \%$, giving information on the small size of the effect. A post hoc analysis confirmed that the difficulty responses were significantly higher for session D 
than for session A $(p<0.001)$ and than for session $\mathrm{C}(p<0.05)$. However, mean difficulty ratings remained below 5 out of 10 for the four sessions.

\section{Effects of noise and vibration levels on annoyance responses for both methods}

The effects of noise and vibration levels on $A_{N}, A_{V}$ and $A_{T}$ were analyzed to investigate the similarity of trends between sessions $\mathrm{A}, \mathrm{B}$ and $\mathrm{C}$ on the one hand, and session $\mathrm{D}$ on the other hand. Six two-factorial RM-ANOVAs were conducted with factors NOISE and VIBRATION levels (four levels per factor).

\section{Partial noise annoyance responses}

The effect of noise level on $A_{N}$ was significant, whether the responses were collected during session $\mathrm{A}\left[F(3,93)=157.49, p<0.001, \eta^{2}=47.5 \%\right]$ or during session $\mathrm{D}[F(3,93)=146.20$, $\left.p<0.001, \eta^{2}=44.8 \%\right]$. The effect of vibration level on $A_{N}$ collected during sessions $\mathrm{A}$ and $\mathrm{D}$ was not significant, $[F(3,93)=2.70, p>0.05]$ and $[F(3,93)=1.13, p>0.34]$, respectively.

\section{Partial vibration annoyance responses}

The effect of vibration level on $A_{V}$ collected during sessions $\mathrm{B}$ and $\mathrm{D}$ was significant with a large effect size, $\left[F(3,93)=75.47, p<0.001, \eta^{2}=24.2 \%\right]$ and $[F(3,93)=77.83$, $p<0.001, \eta^{2}=19.7 \%$, respectively. On the one hand, the effect of the noise level on $A_{V}$ collected during session $\mathrm{B}$ was significant $\left[F(3,93)=3.75, p<0.015, \eta^{2}=0.6 \%\right.$, but the effect size was very small. The result of a post hoc analysis indicated that when the noise level was $62 d B(A), A_{V}$ differed significantly from $A_{V}$ when the noise level was below 56 $d B(A)$. On the other hand, no influence of the noise level on $A_{V}$ collected during session $\mathrm{D}$ was observed $[F(3,93)=0.11, p>0.95]$.

\section{Total annoyance responses}

The effects of both the noise and vibration levels on the $A_{T}$ responses collected during session $\mathrm{C}$ were significant, $\left[F(3,93)=127.85, p<0.001, \eta^{2}=35.9 \%\right]$ and $[F(3,93)=28.94$, 
$\left.p<0.001, \eta^{2}=5.8 \%\right]$, respectively. The effects of both the NOISE and VIBRATION levels on the $A_{T}$ responses collected during session $\mathrm{D}$ were also significant, $[F(3,93)=92.86$, $\left.p<0.001, \eta^{2}=25.1 \%\right]$ and $\left[F(3,93)=18.21, p<0.001, \eta^{2}=2.9 \%\right]$, respectively. There was a significant interaction between the two factors on the $A_{T}$ responses collected during sessions $\mathrm{C}$ and $\mathrm{D},\left[F(9,279)=3.13, p<0.002, \eta^{2}=1.5 \%\right]$ and $[F(9,279)=2.34, p<0.016$, $\left.\eta^{2}=1 \%\right]$, respectively.

\section{DISCUSSION}

Regarding the results of the three one-factorial RM-ANOVAs carried out on $A_{N}$ (collected during sessions $\mathrm{A}$ and $\mathrm{D}$ ), $A_{V}$ (collected during sessions $\mathrm{B}$ and $\mathrm{D}$ ) and $A_{T}$ (collected during sessions $\mathrm{C}$ and D) with factor SESSION, it seems that the factor session (i.e. the method) had no influence on the partial and total annoyance responses. However, the method of collecting the annoyance responses seems to have had a small effect on task difficulty.

The results of the six two-factorial RM-ANOVAs conducted with the factors NOISE and VIBRATION levels suggest that the presence of vibration did not have any influence on the $A_{N}$ responses. This finding is in agreement with the conclusions of previous laboratory studies (e.g. [10]). However, other research works conducted in the laboratory and in situ (e.g. [13]) showed that this influence may exist and therefore contradict this conclusion. In a laboratory experiment, Paulsen and Kastka [11] showed that noise annoyance tends to increase with vibration magnitude only for low to moderate noise levels. However, the noise levels used in their experiment were quite low compared to those used in other studies (e.g. [10] and the current study). This difference in the noise levels could explain the differences between the results of these studies.

The noise level seems to have had an influence on the $A_{V}$ collected during session B. Although this result is consistent with other studies $([10],[11],[13])$, this influence was not found when the $A_{V}$ were collected during session D. Although the proportion of variance $\eta^{2}$ explained by the noise level during session B was very small (less than 1\%). Therefore the effect of the noise level highlighted on $A_{V}$ was very weak.

Both noise and vibration levels influenced $A_{T}$. According to the proportions of variance explained by the two factors, $A_{T}$ is mainly influenced by noise. This result is in agreement with several laboratory and in situ studies ([10],[11],[13]). 


\section{CONCLUSION}

The purpose of this study was to compare two methods of collecting annoyance responses in laboratory conditions: their collection during the same session or during separate sessions. Four sessions with 16 combined noise and vibration stimuli were designed to achieve this goal. During the first session (A), the task was to evaluate partial noise annoyance. During another session (B), the task was to evaluate partial vibration annoyance. The task in the third session (C) was to evaluate total annoyance. Finally during the fourth session (D), the task was to evaluate all three annoyances after each stimulus.

The results indicated that no differences existed between the partial and total annoyance responses collected during the same session and during separate sessions. Session D appeared as rather more difficult for participants. Lastly, session D was suitable as a reduced number of stimuli can lead to as many results as the cumulative sessions A, B and C. Therefore, this laboratory method may be adopted in further experiments in which a larger number of stimuli are used.

\section{ACKNOWLEDGMENTS}

The vibration measurements on site were made possible by Acouphen (www.acouphen.fr). This work was supported by the LabEX CeLyA ("Centre Lyonnais d'Acoustique") of Université de Lyon (ANR-10-LABX-60/ ANR-11-IDEX-007).

[1] P. Lercher, "Combined noise exposure at home," in Encyclopedia of Environmental Health, 764-777 (2011). 
[2] D. C. Waddington, J. Woodcock, E. Peris, J. Condie, G. Sica, A. T. Moorhouse, and A. Steele, "Human response to vibration in residential environments," J. Acoust. Soc. Am. 135, 182-193 (2014).

[3] A. Trollé, C. Marquis-Favre, and E. Parizet, "Perception of annoyance due to vibrations in dwellings generated from ground transportation: A review," J. Low Freq. Noise Vib. Act. Control 34, 413-458 (2015).

[4] B. Berglund, and M. Nilsson, "Empirical issues concerning annoyance models for combined community noises," Proceedings of Internoise 1997, 1317-1322 (1997).

[5] E. Öhrström, L. Barregård, E. Andersson, A. Skånberg, H. Svensson, and P. Ängerheim, "Annoyance due to single and combined sound exposure from railway and road traffic," J. Acoust. Soc. Am. 122, 2642-2652 (2007).

[6] B. Schulte-Fortkamp, and R. Weber, "Overall annoyance ratings in a multisource environment," Proceedings of Internoise 1997, 264-269 (1997).

[7] A. Klein, C. Marquis-Favre, and P. Champelovier, "Assessment of annoyance due to urban road traffic noise combined with tramway noise," J. Acoust. Soc. Am. 141, 231-242 (2017).

[8] A. Trollé, C. Marquis-Favre, and A. Klein, "Short-term annoyance due to tramway noise: Determination of an acoustical indicator of annoyance via multilevel regression analysis," Acta Acust. Acust. 100, 34-35 (2014).

[9] ISO 2631-2 (2003), "Evaluation of human exposure to whole-body vibration. Part 2: Continuous and shock induced vibration in buildings," (International Organisation for Standardization, Geneva, Switzerland).

[10] H. Howarth, and M. Griffin, "Subjective response to combined noise and vibration: summation and interaction effects," J. Sound Vib. 143, 443-454 (1990).

[11] R. Paulsen, and J. Kastka, "Effects of combined noise and vibration on annoyance," J. Sound Vib. 181, 295-314 (1995).

[12] J. Fields, R. De Jong, T. Gjestland, I. Flindell, R. Job, S. Kurra, P. Lercher, M. Vallet, T. Yano, R. Guski, and others, "Standardized general-purpose noise reaction questions for community noise surveys: Research and a recommendation," J. Sound Vib. 242, 641-679 (2001).

[13] A. Gidlöf-Gunnarsson, M. Ögren, T. Jerson, and E. Öhrström, "Railway noise annoyance and the importance of number of trains, ground vibration, and building situational factors," Noise 
Health 14, 190-201 (2012). 